\title{
Development of the Interactive Multimedia Software "Inquiry Play-Room" as an Electronic Learning Resource for Rotation and Equilibrium Topic
}

\author{
https://doi.org/10.3991/ijim.v15i07.21561 \\ Verinda Shavira Sari, Endang Purwaningsih $(\bowtie)$, Winarto, \\ Nugroho Adi Pramono \\ Universitas Negeri Malang, Malang, Indonesia \\ endang.purwaningsih.fmipa@um.ac.id
}

\begin{abstract}
This study reports the development of the interactive electronic multimedia "Inquiry Play-Room" for use in rotation and equilibrium topics. This was designed following the steps of a guided inquiry laboratory model, containing video problems, feedback, virtual laboratories, student worksheets, animations, practical applications, and quizzes. The tests are offered at two levels, one to grasp the concept and the second to be incorporated into actual life. This difference in learning can spur student confidence that will allow them to concentrate. The teacher can also enhance the content quality and patterns of movement through classes and online learning, as this technology is designed for face-to-face use. This interactive media is developed using the SWiSHMax framework and the ActionScript 2.0 programming language. The architecture of this media production model follows these steps: 1) analysis, 2) design, 3) development, 4) implementation, and 5) evaluation. At a 90.3 percent positive rate, the expert testing results indicate feasibility. The results of 27 students showed that the students responded positively to multimedia design. Therefore, the use of interactive multimedia was shown to be possible. The results of this study open avenues for digital creation in other fields of physics.
\end{abstract}

Keywords-Equilibrium, inquiry, interactive multimedia, rotation

\section{Introduction}

The transformation of digital-based learning is a main strategy for facing the challenges of the Industrial Revolution 4.0 era [1]-[3], in which the process of information transmission are very rapid and are reaching a vast area [4], [5]. In addition, physical and virtual reality are becoming more closely incorporated into this age [6]. By this means, digital-based learning is becoming an alternative for helping students access knowledge, conduct learning activities, and understand concepts on several topics [7], [8]. Digital technology can also boost problem-solving [9] and critical thinking skills [10] that students need in the current age. Having advanced, engaging, and immersive digital capabilities can enhance students' effective participation in 
learning experiences [11]. This transformation is ongoing and requires attention in a variety of areas, including physics.

Within the topic of physics, students frequently find it challenging to study equilibrium and rotational motion. Several studies have found that many students labor under misconceptions regarding equilibrium and dynamics concepts [12], [13]. Fang [14] found that many students have a weak understanding of the relationship between impulse and linear momentum and that between impulse and angular momentum, and the relationship between impulse and angular momentum is difficult for them to understand with the law of conservation of angular momentum. Students also have difficulty with basic concepts such as those of torque, rotational inertia, rotational kinetic energy, rotational motion with friction, and the application of the law of conservation of energy law to rotational motion [15]-[17]. Students are often challenged to classify a case as a balanced or imbalanced entity in the state of the equilibrium of a rigid body [18].

Almost all students can answer questions regarding a simple center of gravity system consisting of point-like objects, but they have difficulty determining the center of mass of objects with a continuous mass distribution [19]. Students' misconceptions are rooted in learning activities focused on mathematical analysis, as their participation in appropriate learning activities is limited; they usually only record facts, memorize formulas, and solve questions that only require mathematical calculations [20]. Other formulas memorized by students challenge them to determine which formulas are most suitable for problem-solving [21], [22].

Due to these challenges, several studies have been carried out in the development of learning media to allow students to study equilibrium and rotational dynamics. Yusuf, Mujasam, Widyaningsih, and Djalimun [23] shared best practices to improve students' higher-order thinking skills using simple multimedia. They found that simple multimedia if developed effectively, could be used to this end. However, implementation is limited because the learning process requires more guidance from the teacher. The interactive multimedia development of their product was described by Widodo, Yennita, Azhar, and Islami [24]. However, their only concepts, images, and animations were presented, without any other variation. In a similar vein, Kasih [25] presented the effects of animated films to improve students' understanding of the concept of equilibrium. Successfully used media were often not interactive. Interactive multimedia was also developed by Wahyudin [26], in which students were immediately given concepts, formulas, question exercises, and evaluations of 10 questions. Unfortunately, the students were required to write the answers on paper first and give them to the instructor so that the multimedia approach lost its effectiveness for learning. The interactive multimedia that has been developed so far tends to be monotonous. The content is also mostly viewed in classrooms on computer screens. Further, the multimedia used also does not generally provide feedback that allows students to understand. Updates that include more diverse learning activities can be performed through interactive multimedia. Launching from the description above, the problems discussed in this research concern the ways of developing feasible interactive multimedia that can enable students to enjoy and understand the concept of dynamic rotation and equilibrium. 
The interactive multimedia developed is different from available multimedia. The development process directly includes students in the discovery of concepts and solving problems. It is likewise important that this multimedia project is developed using a model that is already well-established, namely a guided inquiry laboratory. The steps of the model include 1) observation, 2) manipulation, 3) generalization, 4) verification, and 5) application [27]. This learning-based inquiry is positively correlated with the ability of scientific reasoning, in which students are required to follow a process that is systematic and purposeful, beginning with identifying a problem, proposing a hypothesis, identifying variables, conducting an experiment, analyzing data, and drawing valid conclusions [28]. The model characteristics indicate that the students must conduct experiments. However, resources for experimenting on equilibrium and rotational dynamics are not available in many classrooms, posing a barrier to teaching rotational dynamics and equations with this model. Virtual laboratories should be used for interactive multimedia that will be created. Using a virtual classroom, time productivity and comprehension of student topics will improve, influencing learning outcomes [29]-[32]. In addition, with a virtual laboratory, students can experiment flexibly at home if they are not satisfied with the experiments conducted in class [33], [34]. Adopting an interactive digital virtual laboratory, students can communicate and explore directly in the app without having to open another application to present answers in experimental activities through a virtual laboratory. In the final stage of the study, interactive multimedia students can be guided to take up the principles that have been learned in terms of a question or everyday use.

The interactive multimedia that is developed does not contribute to the content's use. As an assessment of learning, the quiz format can be carried out based on reference to basic competencies on two levels of questions that have different cognitive levels. This can reduce the use of tedious examinations, where the students use only forms, numbers entered, and results measured. A two-level quiz, followed by results and feedback, informs the instructor directly where student errors are, which will allow the teacher to effectively evaluate student knowledge of the student without manual correction of the exam.

\section{$2 \quad$ Method}

This study adopted the ADDIE research and development design, carried in the following stages: 1) analysis, 2) design, 3) development, 4) implementation, and 5) evaluation. In the analysis phase, a literature study was conducted to identify students' difficulties in the study of rotational dynamics and equilibrium. We also discovered weaknesses in the interactive multimedia products that had been developed. In the design stage, the product draft was designed in the form of a storyboard and program navigation, along with its specifications. At the development stage, all scenes built into the product were produced and combined. Then, validation was performed, based on the eligibility criteria for interactive multimedia [35]. At the implementation stage, the product was tested on several high school students. The students assessed the multimedia and provided responses through a questionnaire. During the evaluation 
phase, the products that were tested were limited for evaluation for readability, adopting the results of the questionnaire response analysis. The research and development procedure can be seen in Figure 1.

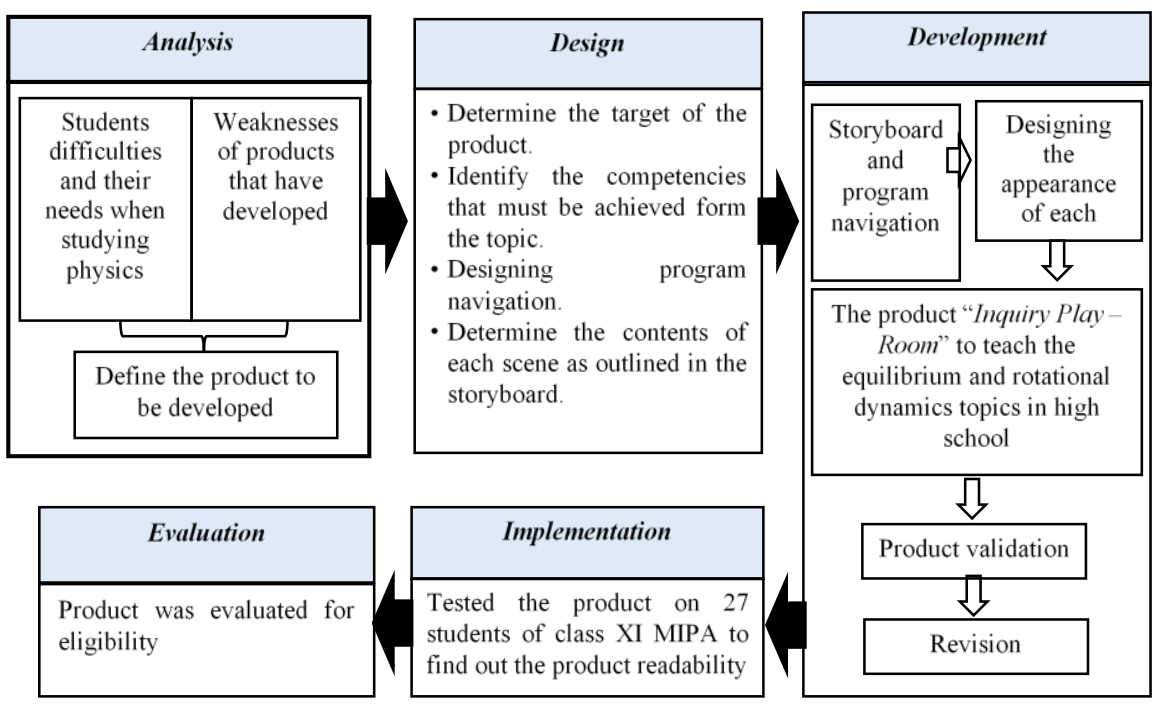

Fig. 1. Research and Development Procedure

Data collection was conducted in the form of an expert validation sheet to determine the validity of the products that were developed, and student questionnaire responses were used to determine product usability. The expert validation data thus obtained were analyzed using the percentage score technique. The score given by each validator was interpreted using the product validity criteria shown in Table 1.

Table 1. Criteria for Product Validity

\begin{tabular}{|c|l|}
\hline Score & \\
\hline $81-100 \%$ & Criteria \\
\hline $61-80 \%$ & Valid \\
\hline $41-60 \%$ & Moderately valid \\
\hline $21-40 \%$ & Slightly valid \\
\hline $0-20 \%$ & Invalid \\
\hline
\end{tabular}

Adapted from: [36]

\section{Results and Discussion}

The concept of rotational dynamics and equilibrium consists of five parts, namely torque, moment of inertia, equilibrium of rigid bodies, center of mass, and conservation of angular momentum. For each element, the concepts presented follow the steps of a guided inquiry laboratory model ranging across observation, manipulation, gen- 
eralization, verification, and application activities. When the students open each submission, a video is displayed, and students are asked to observe certain things in it. Then, the students are asked to perform a simple demonstration according to the instructions and choose the correct statements in accordance with the video and the demonstration as a first step in identifying problems. Students are given feedback according to their answers. After they formulate the problem, students are directed to switch to the virtual laboratory using a shortcut button given in the scene. In a virtual laboratory room, the students are asked to write a hypothesis first. In the virtual laboratory room, a tool and a student worksheet are also present. It is suggested that students concentrate on the worksheets of their classmates and then perform a virtual experiment that is already in multimedia. This follows the work of Karlsson, Ivarsson, and Lindström [37], which confirms that the virtual laboratory as a learning resource is an environment in which students can discuss the concept of solutions, but in this case, the students should be able to answer questions outside of the virtual laboratory. While training, students can directly complete the worksheet in the given space without having to write create a separate document. After the action in the virtual laboratory is complete, the scene presents an animated concept, with guidance for accessing certain web pages for widespread horizons relevant to the subject, such as the concept of force on joints, helicopter-rotor cinematic strength, the focal point for mass of the Earth-Moon system, and so on. After completion, students engage in two difficulty quizzes. The first measures their understanding of concepts, and the second measures their ability to apply the concepts learned for other phenomena.

A navigation system and storyboard are developed to help prepare the product based on the product design. Figure 2 illustrates the software navigation in terms of a flow chart of the contents of the software, as illustrated through the interactivity aspects of interactive multimedia. We then continue to create the storyboard in the form of button layouts, images, text, tables, black text, animations, videos, and scripts for each element, where each view is drawn up as a guide. Products that are easy to use and have complete functions are produced using the SWiSHMax application, which allows maximum user creativity. 


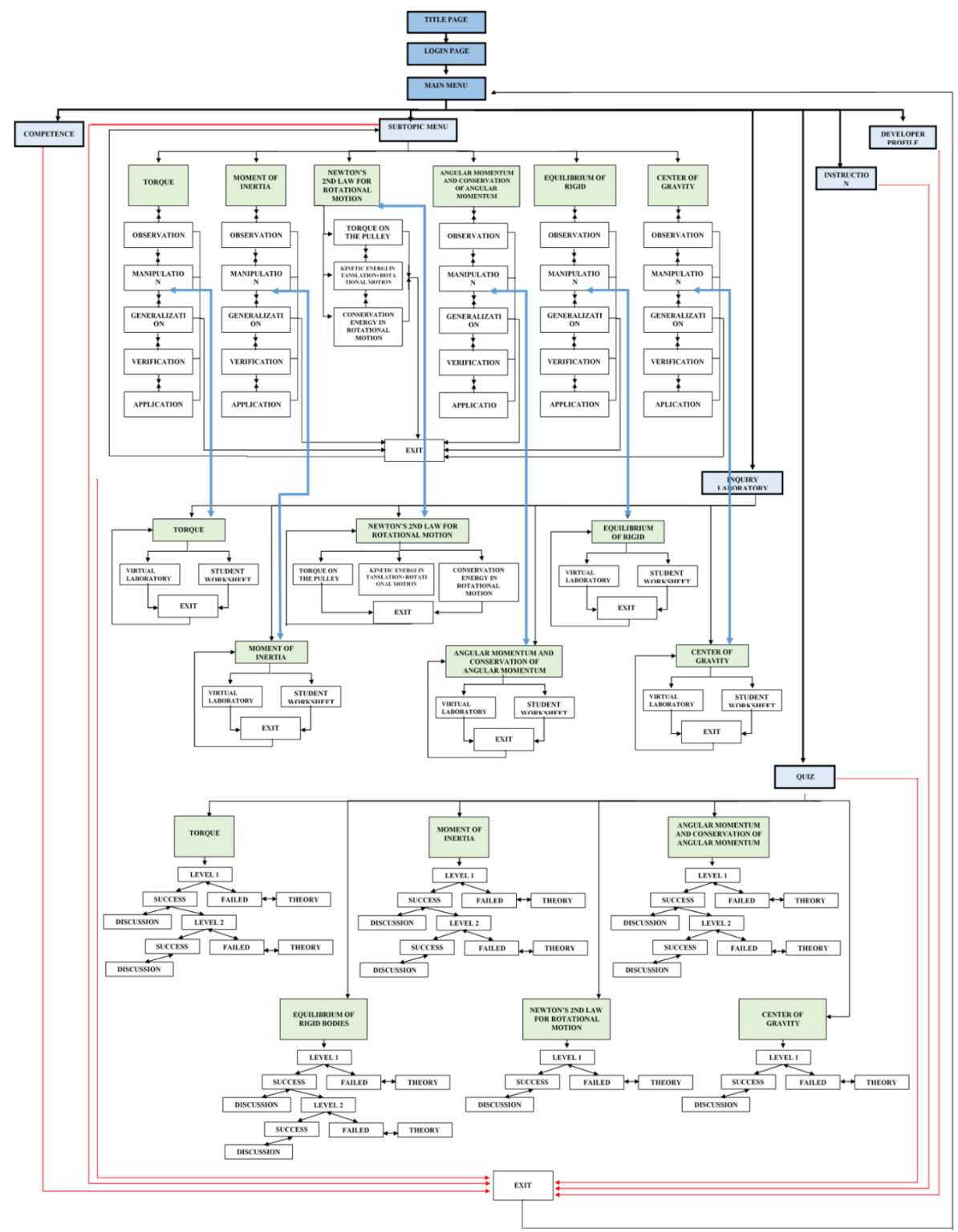

Fig. 2. Program Navigation 


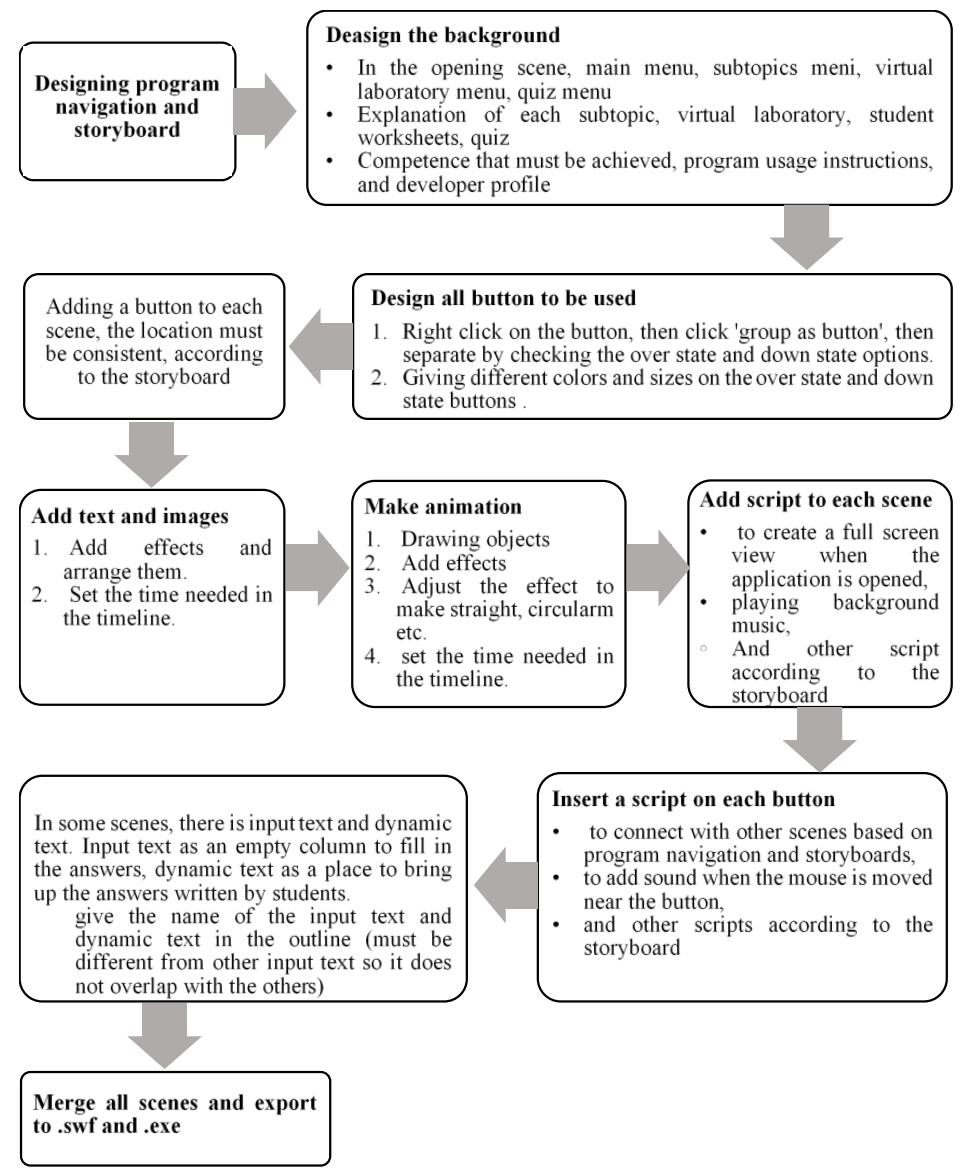

Fig. 3. Procedure for Developing an Inquiry Play-Room

An inquiry play-room has many benefits in the absence of interactive media. Concept presentation is organized based on the steps of the guided research lab model to enable study with the use of virtual experiments, not only to present concepts from books, such as interactive multimedia that were widely circulated, finding concepts and scientific reasoning abilities. The fact that virtual laboratories are available for goods could ameliorate the lack of equipment in schools and give students the opportunity for virtual experimentation. In contrast to interactive multimedia, which only serves as teachers' media, this multimedia involves students in the use of interactive multimedia. In conducting virtual experiments, students are assisted with the students' worksheet, equipped with input text in tables, data analysis, and conclusions. Students can write answers directly, and these are automatically saved by the application without the need for other applications. Some interactive multimedia that has circulated adds students' worksheets as attachments. Still, students must first download it and then open another application to supply the answers, which wastes time. The product is also equipped with an evaluation in the form of a quiz with two levels of difficulty; 
one is the first level, the students understand the concepts in the submission, and the second examines the student's ability to apply the concepts obtained on the application questions. Feedback at each level is adjusted to the score obtained by the students. If students exceed the minimum score at the first level, they are directed to work on the second. If they do not exceed the minimum score, then they are required to repeat the quiz at that level. The quiz format created by the two levels is never applied to interactive multimedia that has been circulating. Even certain interactive multimedia provides no feedback; students must write their replies on paper and wait for the teacher's manual evaluation. By the end of each discussion segment, the students navigate to the website where the applications to the concept being studied are introduced and how the formula can be obtained as a complimentary digital interactive, which does not apply to the application of each part of the concept. Through this interactive multimedia, students are encouraged to learn from a vast amount of misunderstandings about the balance and rotation dynamics and eradicate them. The teacher is also be assisted in learning using a guided inquiry laboratory model in faceto-face and online learning.

\subsection{Expert validation}

The validation is performed in relation to the feasibility of interactive multimedia by a programming expert teacher and a physics expert at Universitas Negeri Malang, as well as a teacher of physics at a high school in Malang. The validation questionnaire used is arranged in relation to the eligibility criteria of interactive multimedia, following Thorn [35]. The recapitulation of the results from the expert validation data results for each aspect is given in Table 2 .

Table 2. Interactive Multimedia Validation Data Recapitulation

\begin{tabular}{|c|l|c|c|c|c|}
\hline \multirow{2}{*}{ No. } & \multirow{2}{*}{ Assessed Aspect } & \multicolumn{3}{|c|}{ Score } & \multirow{2}{*}{ Criteria } \\
\cline { 3 - 5 } & & Validator 1 (\%) & Validator 2 (\%) & Average (\%) & \\
\hline 1. & Ease of Use and Navigation & 87.5 & 100 & 93.8 & Very Valid \\
\hline 2. & Cognitive Content & 94.7 & 89.9 & 92.3 & Very Valid \\
\hline 3. & $\begin{array}{l}\text { Knowledge Space and } \\
\text { Presentation }\end{array}$ & 100 & 87.5 & 93.8 & Very Valid \\
\hline 4. & Media Integration & 75 & 75 & 75 & Valid \\
\hline 5. & Aesthetics & 95.8 & 79.2 & 87.5 & Very Valid \\
\hline 6. & Overall Functionality & 86.1 & 77.8 & 81,9 & Very Valid \\
\hline \multicolumn{2}{|l|}{ Average Score } & 93 & 87.7 & 90.3 & Very Valid \\
\hline
\end{tabular}

Table 2 shows an average score of $90.3 \%$ for all items, indicating highly valid. For convenience and navigation, a $93.8 \%$ score is achieved, indicating high validity, such that the product functions easily and well without special qualifications. A score of $92.3 \%$ for cognitive content is obtained, indicating high validity. Thus, definitions are given in accordance with the directed laboratory model investigation measures. The proposed definition conforms to theoretical physics. It is also necessary to provide examples of questions and logical truths in the discussion of examples. In addition, 
miniature games are also suitable for questions and suggestions or discussion. The experimental exercises in the investigation lab also motivate students to determine their ideas. The knowledge and presentation are rated at $93.8 \%$, very valid. This indicates that the delivery of the product information is specifically given through a straightforward and communication-oriented language, along with illustrations to assist student understanding. A score of $75 \%$ is given for media integration, such that the product is able to assist students to improve their skills in virtual labs, analyze test data, and promote autonomous learning. Thus, it achieves validity. The aesthetic aspect is $87.5 \%$ and can be categorized as highly valid, which means that the product display shows aspects of beauty in terms of both design, selection of background colors, color, text type, animation, video, and background music. In terms of its overall usefulness, the value is $81.9 \%$, a very real rating, meaning that the product can provide students with the necessary learning environment, including increased motivation, enhanced conception, practical scientific thinking, and effective and productive learning. This is in line with the study of Makransky and Lilleholt [38], who, using a virtual laboratory in the form of virtual reality, find that student motivation significantly affected student enjoyment and motivation.

\subsection{Pilot study}

The revised products are then used in limited trials performed with 27 students in their second year at SMAN 1 Malang, a senior high school in Malang. All students report that a) the product can be run and operated easily: b) instructions for use are clear and easy to understand; c) navigation buttons are easy to find and use; d) design and appearance are attractive, experiments are easy to do, quiz formats fun; and e) the product can help in understanding the concepts of equilibrium and rotational dynamics. In addition, 26 of the 27 students report that: a) the type, size, and color of the font was attractive and can be read clearly; b) the animation or video used is interesting; c) the text, image, description, and animation are well placed, d) the animation can help in understanding the concepts, and e) the questions on the mini-games are easy to understand; student reports otherwise. Then, 25 out of 27 students report that: a) the delivery of the concepts is easy to understand, b) the product can help them learn independently, and c) the product can train them to operate a virtual laboratory and analyze experimental data, with two students report otherwise. This result is in harmony with the work of $\mathrm{Ng}$ and Fergusson [39], who found that teachers in their study considered that learning by utilizing technology could increase their students' self-confidence to learn independently. However, their students were challenged to transfer their newly created information to understand how anomalous data findings could have occurred [40]. In all, 23 of the 27 students stated that the product developed can increase their motivation in understanding the concept of equilibrium and rotational dynamics, while 4 states the opposite. Then, 21 out of 27 students state that the background music is appropriate, while 6 students state the opposite. Buttons should be added to the product to turn the music on and off. An analysis of the students' answers indicate that the product "Inquiry Play-Room" is feasible to teach equilibrium and the dynamics of rotation in high school. 


\section{Conclusion}

Interactive electronic multimedia is developed to teach equilibrium and rotation motion. This software is developed using the SWiSHMax framework and ActionScript 2.0 to incorporate virtual laboratories and worksheets for students to store responses. Students can use it to find concepts independently whenever and wherever, and the product can be used in online learning beyond face-to-face situations in class. The results of expert validation obtained a score of $90.3 \%$, indicating a very valid categorization. Based on the results of the pilot study with 27 students, it can be concluded that the developed interactive multimedia is feasible. This study shows that the product developed can be used for self-learning, provide clear instruction to students in running a virtual laboratory, and analyze experimental results. This can make the concepts easily understandable. However, this study has some limitations. We recommend that this product be disseminated and tested across a wider range of participants. It is also possible to develop similar multimedia products with other content.

\section{$5 \quad$ References}

[1] A. Benešová and J. Tupa, "Requirements for Education and Qualification of People in Industry 4.0," Procedia Manufacturing, vol. 11, pp. 2195-2202, 2017, https://doi.org/10.10 16/j.promfg.2017.07.366.

[2] A. Oke and F. A. P. Fernandes, "Innovations in Teaching and Learning: Exploring the Perceptions of the Education Sector on the 4th Industrial Revolution (4IR)," JOItmC, vol. 6, no. 2, p. 31, Apr. 2020, https://doi.org/10.3390/joitmc6020031.

[3] A. A. Shahroom and N. Hussin, "Industrial Revolution 4.0 and Education," IJARBSS, vol. 8, no. 9, p. Pages 314-319, Oct. 2018, doi: 10.6007/IJARBSS/v8-i9/4593.

[4] M. Baygin, H. Yetis, M. Karakose, and E. Akin, "An effect analysis of industry 4.0 to higher education," in 2016 15th International Conference on Information Technology Based Higher Education and Training (ITHET), Istanbul, Turkey, Sep. 2016, pp. 1-4, https ://doi.org/10.1109/ithet.2016.7760744.

[5] A. Svela, J. Nouri, O. Viberg, and L. Zhang, "A Systematic Review of Tablet Technology in Mathematics Education,” Int. J. Interact. Mob. Technol., vol. 13, no. 08, p. 139, Aug. 2019, https://doi.org/10.3991/ijim.v13i08.10795.

[6] K. Schuster, K. Groß, R. Vossen, A. Richert, and S. Jeschke, "Preparing for Industry 4.0 Collaborative Virtual Learning Environments in Engineering Education," in Engineering Education 4.0, S. Frerich, T. Meisen, A. Richert, M. Petermann, S. Jeschke, U. Wilkesmann, and A. E. Tekkaya, Eds. Cham: Springer International Publishing, 2016, pp. 477487. https://doi.org/10.1007/978-3-319-46916-4 36

[7] A. A. Hussin, "Education 4.0 Made Simple: Ideas For Teaching," IJELS, vol. 6, no. 3, pp. 92-98, Jul. 2018, https://doi.org/10.7575/aiac.ijels.v.6n.3p.92.

[8] J. P. Brown, "Complexities of digital technology use and the teaching and learning of function,” Computers \& Education, vol. 87, pp. 112-122, Sep. 2015, https://doi.org/10.10 16/j.compedu.2015.03.022.

[9] C. Andreucci, M. Chatoney, and J. Ginestie, "The systemic approach to technological education: effects of transferred learning in resolving a physics problem," Int J Technol Des Educ, vol. 22, no. 3, pp. 281-296, Aug. 2012, https://doi.org/10.1007/s10798-010-9148-y. 
[10] H. Haerazi, I. M. P. Utama, and H. Hidayatullah, "Mobile Applications to Improve English Writing Skills Viewed from Critical Thinking Ability for Pre-Service Teachers," Int. J. Interact. Mob. Technol., vol. 14, no. 07, p. 58, May 2020, https://doi.org/10.3991/ijim. v14i07.11900.

[11] J. AlAmmary, "Educational Technology: A Way to Enhance Student Achievement at the University of Bahrain," Procedia - Social and Behavioral Sciences, vol. 55, pp. 248-257, Oct. 2012, https://doi.org/10.1016/j.sbspro.2012.09.501.

[12] P. Barniol, G. Zavala, and C. Hinojosa, "Students' difficulties in interpreting the torque vector in a physical situation," Philadelphia, PA, USA, 2013, pp. 58-61, https://doi.org/10. $1063 / 1.4789651$.

[13] E. M. Jannah and F. U. Ermawati, "Identify 11th Grade of Senior High School Jogoroto students' misconceptions on Dynamic Rotation and Rigid Body Equilibrium concepts using Four-Tier Diagnostic Test,” J. Phys.: Conf. Ser., vol. 1491, p. 012010, Mar. 2020, https ://doi.org/10.1088/1742-6596/1491/1/012010.

[14] N. Fang, "Students' Perceptions of Dynamics Concept Pairs and Correlation with Their Problem-Solving Performance," J Sci Educ Technol, vol. 21, no. 5, pp. 571-580, Oct. 2012, https://doi.org/10.1007/s10956-011-9347-7.

[15] H. G. Close and P. R. L. Heron, "Student understanding of the angular momentum of classical particles," American Journal of Physics, vol. 79, no. 10, pp. 1068-1078, Oct. 2011, https://doi.org/10.1119/1.3579141.

[16] İ. Duman, N. Demrici, and A. Sekercioğlu, "University Students' Difficulties and Misconceptions on Rolling, Rotational Motion and Torque Concepts," International Journal on New Trends in Education and Their Implications, vol. 6, no. 1, pp. 46-54, 2015.

[17] L. G. Rimoldini and C. Singh, "Student understanding of rotational and rolling motion concepts,” Phys. Rev. ST Phys. Educ. Res., vol. 1, no. 1, p. 010102, Oct. 2005, https://doi. org/10.1103/physrevstper.1.010102.

[18] J. L. Newcomer, "Correlation of Students' Basic Understanding of Rigid Body Dynamics and Performance in Statics," presented at the 120th ASSE Annual Confrence \& Exposition, Jun. 2013. https://doi.org/10.18260/1-2--19358

[19] L. G. Ortiz, P. R. L. Heron, and P. S. Shaffer, "Student understanding of static equilibrium: Predicting and accounting for balancing," American Journal of Physics, vol. 73, no. 6, pp. 545-553, Jun. 2005, https://doi.org/10.1119/1.1862640.

[20] S. E. Nugroho and Waslam, "Physics experiment activities to stimulate interest in learning physics and reasoning in high school students," J. Phys.: Conf. Ser., vol. 1567, Jun. 2020, https://doi.org/10.1088/1742-6596/1567/2/022069.

[21] A. Bray and J. Williams, "Why is physics hard? Unpacking students' perceptions of physics,” J. Phys.: Conf. Ser., vol. 1512, p. 012002, Apr. 2020, https://doi.org/10.1088/17426596/1512/1/012002

[22] I. Phage, "Undergraduate students' difficulties with motion of objects on horizontal and inclined surfaces," J. Phys.: Conf. Ser., vol. 1512, p. 012014, Apr. 2020, https://doi.org/ 10.1088/1742-6596/1512/1/012014.

[23] I. Yusuf, Mujasam, S. W. Widyaningsih, and S. Djalimun, "Best practice to improve students' HOTS using simple tool media-based learning in group investigation model at the State Senior High School 1 Manokwari," J. Phys.: Conf. Ser., vol. 1321, p. 032080, Oct. 2019, https://doi.org/10.1088/1742-6596/1321/3/032080.

[24] A. Widodo, Yennita, Azhar, and N. Islami, "Development of Physics Learning Media on Rotational Materials Based on Interactive Multimedia," J. Phys.: Conf. Ser., vol. 1351, p. 012057, Nov. 2019, https://doi.org/10.1088/1742-6596/1351/1/012057. 
[25] F. R. Kasih, "Pengembangan Film Animasi dalam Pembelajaran Fisika pada Materi Kesetimbangan Benda Tegar di SMA [Development of Animated Films in Physics Learning on Solid Object Equilibrium Material in High School]," Tadris, vol. 2, no. 1, p. 41, Jun. 2017, https://doi.org/10.24042/tadris.v2i1.1737.

[26] C. Wahyudin, "Pengaruh Multimedia Interaktif Terhadap Hasil Belajar Siswa pada Konsep Dinamika Rotasi dan Kesetimbangan Benda Tegar [Effect of Interactive Multimedia on Student Learning Outcomes on the Concept of Rotational Dynamics and Eqilibrium of Rigid Body]," UIN Syarif Hidayatullah Jakarta, Jakarta, 2016. https://doi.org/10.12928/ irkpf.v7i1.16058

[27] C. J. Wenning, "Levels of inquiry: Hierarchies of pedagogical practices and inquiry processes," J. Phys. Tchr. Educ. Online, vol. 2, no. 3, pp. 3-12, 2005.

[28] N. Novia and R. Riandi, "The Analysis of Students Scientific Reasoning Ability in Solving the Modified Lawson Classroom Test of Scientific Reasoning (MLCTSR) Problems by Applying the Levels of Inquiry," JPII, vol. 6, no. 1, pp. 116-122, Apr. 2017, https://doi. org/10.15294/jpii.v6i1.9600.

[29] S. M. Dewi, G. Gunawan, A. Harjono, S. Susilawati, and L. Herayanti, "Generative learning models assisted by virtual laboratory to improve mastery of student physics concept," J. Phys.: Conf. Ser., vol. 1521, p. 022013, Apr. 2020, https://doi.org/10.1088/17426596/1521/2/022013.

[30] S. L. Qamaria, "The Usage of Virtual Laboratory on Grade 11 Students' Learning Outcomes Toward Physics," presented at the International Conference on Online and Blended Learning 2019 (ICOBL 2019), Yogyakarta, Indonesia, 2020, https://doi.org/10.2991/ass ehr.k.200521.032.

[31] L. Safitri, Fahrudin, and Jumadi, "Comparison of students science process skills after using learning an experimental and virtual laboratory on Archimedes Laws," J. Phys.: Conf. Ser., vol. 1440, p. 012079, Jan. 2020, https://doi.org/10.1088/1742-6596/1440/1/012079.

[32] A. Sypsas, E. Paxinou, and D. Kalles, "Reviewing inquiry-based learning approaches in virtual laboratory environment for science education," ICODL, vol. 10, no. 2A, p. 74, Feb. 2020, https://doi.org/10.12681/icodl.2288.

[33] K. El Kharki, F. Bensamka, and K. Berrada, "Enhancing Practical Work in Physics Using Virtual Javascript Simulation and LMS Platform," in Radical Solutions and eLearning, D. Burgos, Ed. Singapore: Springer Singapore, 2020, pp. 131-146. https://doi.org/10.1007/9 78-981-15-4952-6 9

[34] D. Darmawan, "Development of ICMLS Version 2 (Integrated Communication and Mobile Laboratory Simulator) To Improve 4.0 Century Industry Skills in Vocational Schools,” Int. J. Interact. Mob. Technol., vol. 14, no. 08, p. 97, May 2020, https://doi.org/ 10.3991/ijim.v14i08.12625.

[35] W. J. Thorn, "Points to Consider when Evaluating Interactive Multimedia," The Internet TESL Journal, vol. 2, no. 4, 1995.

[36] Riduwan, Dasar-dasar Statistika. Bandung: Penerbit Alfabeta, 2018.

[37] G. Karlsson, J. Ivarsson, and B. Lindström, "Agreed discoveries: students' negotiations in a virtual laboratory experiment," Instr Sci, vol. 41, no. 3, pp. 455-480, May 2013, https:// doi.org/10.1007/s11251-012-9238-1.

[38] G. Makransky and L. Lilleholt, "A structural equation modeling investigation of the emotional value of immersive virtual reality in education," Education Tech Research Dev, vol. 66, no. 5, pp. 1141-1164, Oct. 2018, https://doi.org/10.1007/s11423-018-9581-2.

[39] W. Ng and J. Fergusson, "Technology-Enhanced Science Partnership Initiative: Impact on Secondary Science Teachers," Res Sci Educ, vol. 49, no. 1, pp. 219-242, Feb. 2019, https ://doi.org/10.1007/s11165-017-9619-1. 
[40] E. E. Toth, "Analyzing 'real-world' anomalous data after experimentation with a virtual laboratory," Education Tech Research Dev, vol. 64, no. 1, pp. 157-173, Feb. 2016, https:// doi.org/10.1007/s11423-015-9408-3

\section{Authors}

Verinda Shavira Sari is a student in Department of Physics, Faculty of Mathematics, and Natural Sciences, Universitas Negeri Malang.

Endang Purwaningsih is an Associate professor in Department of Physics, Faculty of Mathematics, and Natural Sciences, Universitas Negeri Malang. She is a researcher in physics education area and especially in Technological, Pedagogical Content Knowledge (TPACK).

Winarto is an assistant professor in Department of Physics, Faculty of Mathematics, and Natural Sciences, Universitas Negeri Malang He is a lecturer and researcher in programming physics learning media topic.

Nugroho Adi Pramono is an assistant professor in Department of Physics, Faculty of Mathematics, and Natural Sciences, Universitas Negeri Malang. He is a lecturer and researcher in programming physics learning media topic.

Article submitted 2021-01-28. Resubmitted 2021-03-05. Final acceptance 2021-03-06. Final version published as submitted by the authors. 